\title{
Iron Chelating Activity of Gossypitrin Isolated from the Petals of Talipariti elatum Sw. (Fryxell) Malvaceae
}

\author{
José González (Correspondence author) \& Armando Cuéllar \\ Department of Pharmacy, Faculty of Pharmacy and Foods, Havana University, Cuba
}

Tel: 53-7262-6664 E-mail: jgyaque@ifal.uh.cu

Enmanuel Nossin \& Max Monan

ARVARNAM, Martinica

Received: March 30, 2017

Accepted: May 3, 2017

Published: May 4, 2017

doi:10.5296/jas.v5i2.11174

URL: https://doi.org/10.5296/jas.v5i2.11174

\begin{abstract}
A Fe(III)-gossypitrin complex was prepared with a metal to ligand molar ratio of $1: 1 ; 2: 1$ and 3:2 by mixing stoichiometric amounts of gossypitrin and $\mathrm{FeCl}_{3}$. The isolated complex was characterized by visual observation, UV/Vis, IR and ESI-MS spectroscopy. In this study, we selected the major flavonoid glycoside present in the petals of the flowers of Talipariti elatum Sw. (Fryxell) Malvaceae that grows in Cuba, gossypitrin, to characterize the chelating activity of it chemical compound with $\mathrm{FeCl}_{3}$, to find alternative sources with lower side effects in asthmatic patients. A high chelating activity can be observed as a good source of new agents for asthmatic patients.
\end{abstract}

Keywords: Iron chelating, gossypitrin, petals, Talipariti elatum, flavonoids

\section{Introduction}

Flavonoids consist of a large group of polyphenolic compounds having a benzo- $\gamma$-pyrone structure and are ubiquitously present in plants. They are synthesized by phenylpropanoid pathway. Available reports tend to show that secondary metabolites of phenolic nature including flavonoids are responsible for the variety of pharmacological activities (Mahomoodally et al., 2005; Pandey, 2007). Functional hydroxyl groups in flavonoids mediate their antioxidant effects by scavenging free radicals and/or by chelating metal ions (Kumar et al., 2013a; Kumar et al., 2013b). The chelation of metals could be crucial in the prevention of radical generation which damage target biomolecules (Leopoldini et al., 2006; Kumar et al., 2013c). Because of their capacity to chelate metal ions (iron, copper, etc.), 
flavonoids also inhibit free radical generation (Mishra et al., 2013a; Mishra et al., 2013b). Quercetin in particular is known for its iron-chelating and iron-stabilizing properties. Trace metals bind at specific positions of different rings of flavonoid structures (Van et al., 1996). The binding sites are shown in Figure 1.

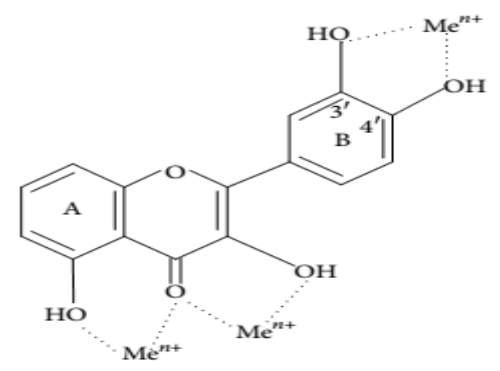

Fig. 1. Binding sites for trace metals where Men+ indicates metal ions

Free metal ions enhance ROS formation by the reduction of hydrogen peroxide with generation of the highly reactive hydroxyl radical. Due to their lower redox potentials flavonoids $(\mathrm{Fl}-\mathrm{OH})$ are thermodynamically able to reduce highly oxidizing free radicals (redox potentials in the range 2.13-1.0 V) such as superoxide, peroxyl, alkoxyl, and hydroxyl radicals by hydrogen atom donation. Because of their capacity to chelate metal ions (iron, copper, etc.), flavonoids also inhibit free radical generation (Mishra et al., 2013a; Mishra et al., 2013b). The flavonoid heterocycle contributes to antioxidant activity by permitting conjugation between the aromatic rings and the presence of a free 3-OH. Removal of a 3-OH annuls coplanarity and conjugation which compromises scavenging ability (Bors et al., 1990).

It is proposed that $\mathrm{B}$ ring $\mathrm{OH}$ groups form hydrogen bonds with the $3-\mathrm{OH}$, aligning the $\mathrm{B}$ ring with the heterocycle and A ring. Due to this intramolecular hydrogen bonding, the influence of a 3-OH is enhanced by the presence of a 3', 4'-catechol, elucidating the potent antioxidant activity of flavan-3-ols and flavon-3-ols that possess the latter feature. Generally O-methylation of hydroxyl groups of flavonoids decreases their radical scavenging capacity (Rice-Evans et al., 1996).

Occurrence, position, structure, and total number of sugar moieties in flavonoid (flavonoids glycosides) play an important role in antioxidant activity. Aglycones are more potent antioxidants than their corresponding glycosides. There are reports that the antioxidant properties of flavonol glycosides from tea declined as the number of glycosidic moieties increased (Ratty and Das, 1988). Though glycosides are usually weaker antioxidants than aglycones, bioavailability is sometimes enhanced by a glucose moiety. In the diet, flavonoid glycosidic moieties occur most frequently at the 3- or 7-position (Hollman et al., 1999).

Flavonoids are good chelating agents towards metal ions and, in the case of iron and copper, the favoured places of chelation are catechol groups, hydroxyl groups adjacent to oxo groups, and 1-oxo-3-hydroxyl-containing moieties (Fernandez et al., 2002; Ren et al., 2008). This ability to chelate metals has been used to enhance the capabilities of MS; it has been used to assist the elucidation of flavonoid glucuronides (Davis et al., 2006; Davis et al., 2007) and 
various diglycosides (Pikulski et al., 2007). This is a result of the spectral changes observed when flavonoids are complexed with metals, giving rise to simpler yet more intense spectra (Satterfield \& Brodbelt, 2000).

For thousands of years, mankind has known about the benefit of drugs from nature. Plant extracts, for the treatment of various ailments, were highly regarded by the ancient civilizations. Even today, plant materials remain an important resource for combating illnesses. Some medicinal plants traditionally used for management of diseases were selected and their phenol and flavonoid content and iron chelating activities were evaluated, including gossypitrin, the major flavonoid glycoside present in the petals of the flowers of Talipariti elatum Sw. (Fryxell) Malvaceae that grows in Cuba.

The structure of the last-mentioned compound remains questionable: gossypitrin was first taken out in 1916 from the flower of Gossypium by Parkin (Parkin, 1916). The aim of this research was to characterize the chelating activity of it chemical compound with $\mathrm{FeCl}_{3}$ to find alternative sources with lower side effects in asthmatic patients.

\section{Material and Methods}

\subsection{Plant Material}

Flowers were collected in January 2015 in the gardens of the Faculty of Pharmacy and Foods at Havana University, and identified at the herbarium of National Botany Garden of Havana, where the voucher specimen no. HAJB 82587 has been deposited. Specimen is registered as Talipariti elatum Sw. (Fryxell) Malvaceae (Sin. Hibiscus elatus Sw.).

\subsection{Chemicals}

Analytical grade ethanol (Merck), analytical grade acetic acid (Merck), analytical grade n-butanol (Merck) and analytical grade methanol (Merck) were used in the analysis work. All solvents were degassing previously before used in an ultrasonic bath without filtration.

\subsection{Extract and Samples Preparation}

Dark red flowering types were collected daily. The isolated petals used were dried in an oven with controlled temperature, at $40^{\circ} \mathrm{C}$, during 5 days. The extracts were prepared with the ground material $(60 \mathrm{~g})$ without screen extracted in a Soxhlet apparatus with $675 \mathrm{~mL}$ of ethanol at 95\% during 20 hours. The ethanolic extracts were concentrated and evaporated under vacuum to $200 \mathrm{~mL}$ at $120 \mathrm{rpm}$, a temperature of $70^{\circ} \mathrm{C}$ and 500 mbar.

For to the purification, $1 \mathrm{~g}$ of solid was dissolved in $25 \mathrm{~mL}$ of diethyl ether and the volume was completed to $100 \mathrm{~mL}$ with ethanol. The sample was refrigerated until an abundant solid appear and it was recuperated to filtration. This process was done twice, to obtain only a yellowish-green solid monitoring by TLC on silica gel with fluorescent indicator $254 \mathrm{~nm}$ on aluminum cards (layer thickness $0.2 \mathrm{~mm})(10 \times 20 \mathrm{~cm})$ using n-butanol: acetic acid: water $(4: 1: 5)$ as eluent $(\mathrm{v} / \mathrm{v} / \mathrm{v})$.

\subsection{Procedures, Instrumentation and Parameters}




\section{Macrothink}

Journal of Agricultural Studies

ISSN 2166-0379

2017, Vol. 5, No. 2

The checking of the behaviour compared with the $\mathrm{Fe}^{3+}$ ions, was enhanced evaluating an extract that contain $12 \mathrm{mg} / \mathrm{mL}$ of ethanol with the ion solutions at $1 \%$ in distilled water, adding $1 \mathrm{~mL}$ of each solution and 3 drops of the reference extract in a test tube, through a visual observation, utilizing water as negative control.

\subsubsection{UV}

The UV spectrometric experiments were carried out on a JASCO ultraviolet-visible spectrometer (Japan). The scan range was 200 to $500 \mathrm{~nm}$, absorbance 0 to 2.5 , and the analysed samples were diluted in methanol, into quartz cuvettes, comparing the obtained spectrum to the recrystallized gossypitrin with and without $\mathrm{FeCl}_{3}$. The cuvettes thickness was $d=1 \mathrm{~cm}$.

\subsubsection{IR}

The IR spectrometric experiments were carried out on a JASCO FT/IR-460 (Japan), Detector TGS, Light Source Standard (Laser Neon), and Resolution $2 \mathrm{~cm}^{-1}$, Scanning Speed 2mm/sec; Scan range $3800-650 \mathrm{~cm}^{-1}$, comparing the obtained spectrum to the recrystallized gossypitrin with and without $\mathrm{FeCl}_{3}$.

\subsubsection{HPLC-UV-ESI-MS}

The LC system consisted of an Agilent 1100 HPLC system (Agilent, Palo Alto, CA) including Degasser (G1322A), Quaternary pump (G1311A), Autosampler (G1313A), Column heater (G1316A) and DAD (G1315B). The HPLC column was a Waters Atlantis C18, 150 $\mathrm{mm} \times 2.1 \mathrm{~mm} \times 3 \mu \mathrm{m}$. Elution was performed at a flow rate of $3 \mathrm{~mL} / \mathrm{min}$., using as eluent (A) $\mathrm{H}_{2} \mathrm{O} 0.1 \%$ and eluent (B) ACN $0.1 \%$. All solvents were degassing previously before used in an ultrasonic bath without filtration. A gradient of $\mathrm{A}=90.0 \%$ and $\mathrm{B}=10.0 \%$ during $3 \mathrm{~min}$, was followed by holding the gradient during $37 \mathrm{~min}$, then changing the gradient of $\mathrm{A}=0.0 \%$ and $\mathrm{B}=100.0 \%$ during $5 \mathrm{~min}$ and reversing to $\mathrm{A}=90.0 \%$ and $\mathrm{B}=10.0 \%$ during $5 \mathrm{~min}$. LC-MS analyses were performed on a ThermoFinnigan (Thermo Electron, San Jose, CA) 3D ion trap mass spectrometer fitted with an Electrospray source. For MS analysis only the positive ion mode of ESI were examined with the scan range from $\mathrm{m} / \mathrm{z} 0$ to 2000. Capillary Temp (C): 275.00, Sheath Gas Flow (ua): 50.00, Aux/Sweep Gas Flow (): 10.00, Source Type: ESI. POSITIVE POLARITY: Source Voltage (kV): 4.50, Capillary Voltage (V): 37.00, Tube Lens Offset (V): 30.00, Multipole RF Amplifier (Vp-p): 400.00, Multipole 1 Offset (V): -4.00 , Multipole 2 Offset (V): -6.00 , InterMultipole Lens Voltage (V): -30.00 .

\section{Results and Discussion}

In the visual checking of the gossypitrin behaviour in from of the $\mathrm{Fe}^{3+}$ ions, the yellow-green colour disappear and the solution become deep black instantaneously. The complexing power of the gossypitrin gave positive values from $25 \mathrm{mg}$ to $2,81 \mathrm{mg}$ (minimum visual reaction limit).

UV spectral results of gossypitrin in $\mathrm{MeOH}$ shows two absorption maximum bands at $\lambda=$ 332 and $382 \mathrm{~nm}$, and show another band at $\lambda=278 \mathrm{~nm}$ with an inflexion at $257 \mathrm{~nm}$ (Fig.2). In contrast with this, the absorption bands in the electronic spectrum of a mixture of 
gossypitrin with Fe (III) chloride changes, and shows new bands at $\lambda=249$ and $366 \mathrm{~nm}$, undergoes a bathochromic shift of $64 \mathrm{~nm}$. The third band disappears. The results suggest a reaction with the iron ion of the reactive (Fig. 3).

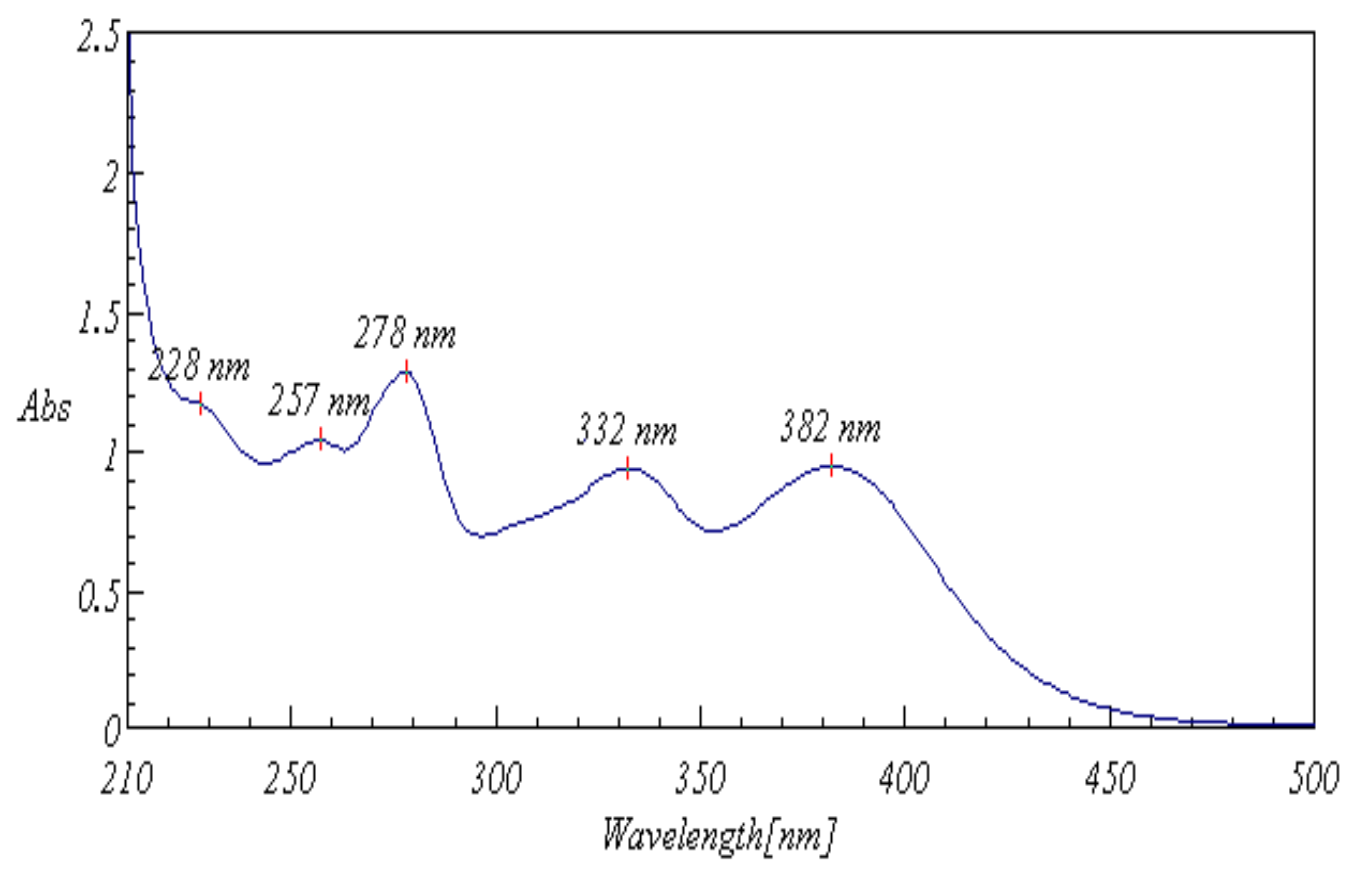

Fig. 2. UV spectrum of gossypitrin without $\mathrm{FeCl}_{3}$

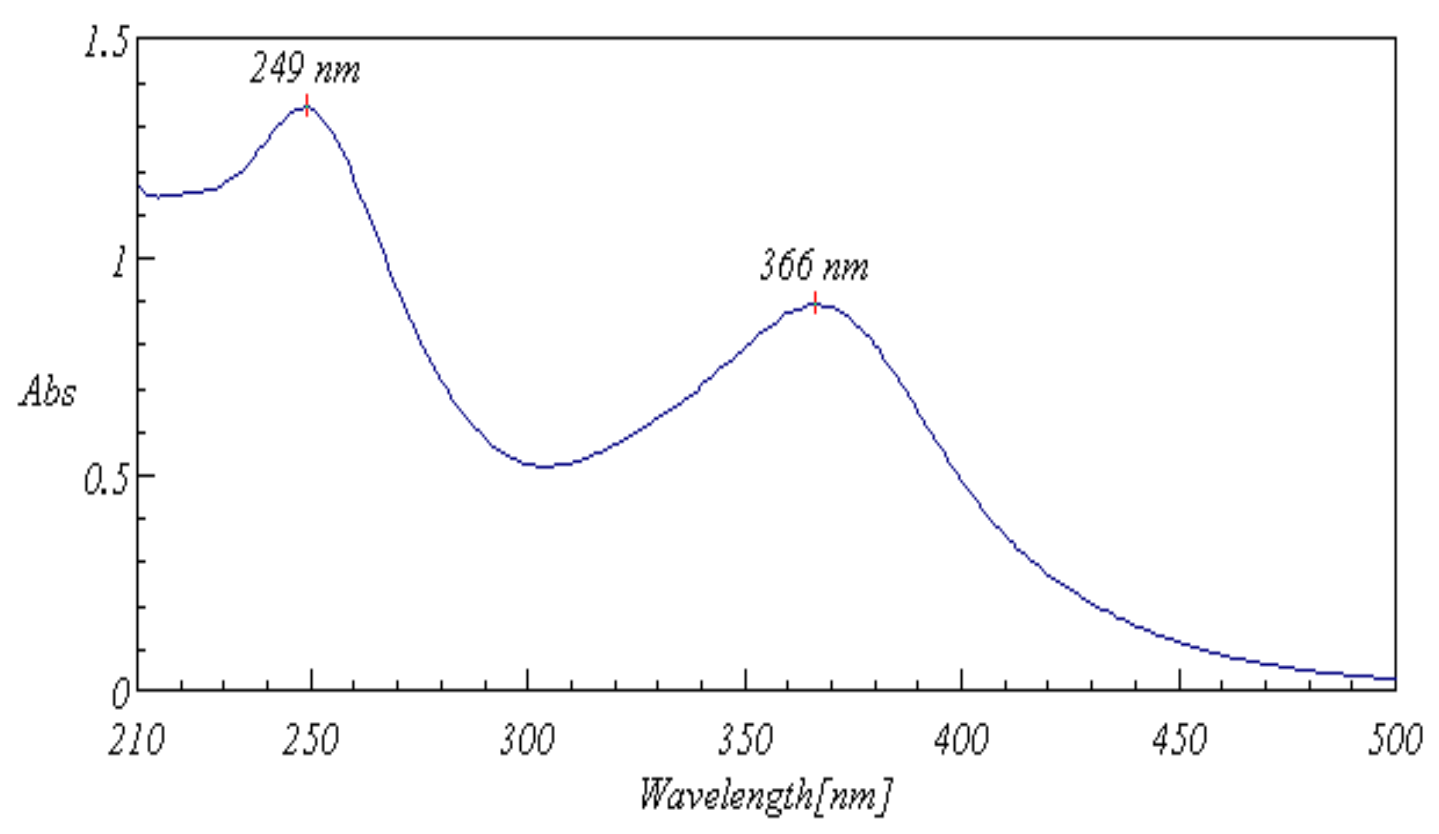

Fig. 3. UV spectrum of gossypitrin with $\mathrm{FeCl}_{3}$

Studies on flavonoids by UV spectroscopy have revealed that most flavones and flavonols exhibit two major absorption bands: Band I (320-385nm) represents the B ring absorption, while Band II (250-285 nm) corresponds to the A ring absorption. 
Electronic spectroscopy provided information about the structure and composition of flavonolate complexes. The literature indicates that changes in the visible spectrum (370-500 $\mathrm{nm}$ ) depend more on the nature of the salts, complexants present, metal salts used to maintain ionic strength, and other factors than those in the UV spectrum (Abad-García et al., 2009). As a rule, changes in the range $250-270 \mathrm{~nm}$ are insignificant (region affected by ring A) whereas those in the visible range $(350-500 \mathrm{~nm})$ reflect changes in the chromone structure and ring $\mathrm{B}$ of the flavonoid (Vukics \& Guttman, 2010). The bathochromic shift of the gossypitrin in this spectral region is probably indicative of the formation of the Fe complexes with the $3^{\prime}, 4^{\prime}-o^{-}$ phenols of ring B (Scheme 1). In general, the UV spectral results confirm the structure (3', $\mathbf{4}^{\prime}-\mathrm{Fe}^{\mathbf{+ 3}}$ ) for the gossypitrin complexes with $\mathrm{FeCl}_{3}$ in solution.

IR spectrum of gossypitrin shows the characteristics bands of this bioflavonoid (Fig. 4):

1. $3228.25 \mathrm{~cm}^{-1} \mathrm{OH}$ stretching vibrations, strongly and broad band of associated alcohols and phenols.

2. $2927.41 \mathrm{~cm}^{-1}$ typical C-H stretching, weak intense band.

3. $1653.66 \mathrm{~cm}^{-1}$ stretching $\mathrm{C}=\mathrm{O}$ band, that in the flavonoids appear so displaced by the high conjugation of the carbonyl group.

4. 1608.34-1523.49 $\mathrm{cm}^{-1}$ stretching $\mathrm{C}-\mathrm{C}$ bands of aromatic compounds.

5. $1195.65 \mathrm{~cm}^{-1}$ stretching $\mathrm{C}-\mathrm{O}$ band.

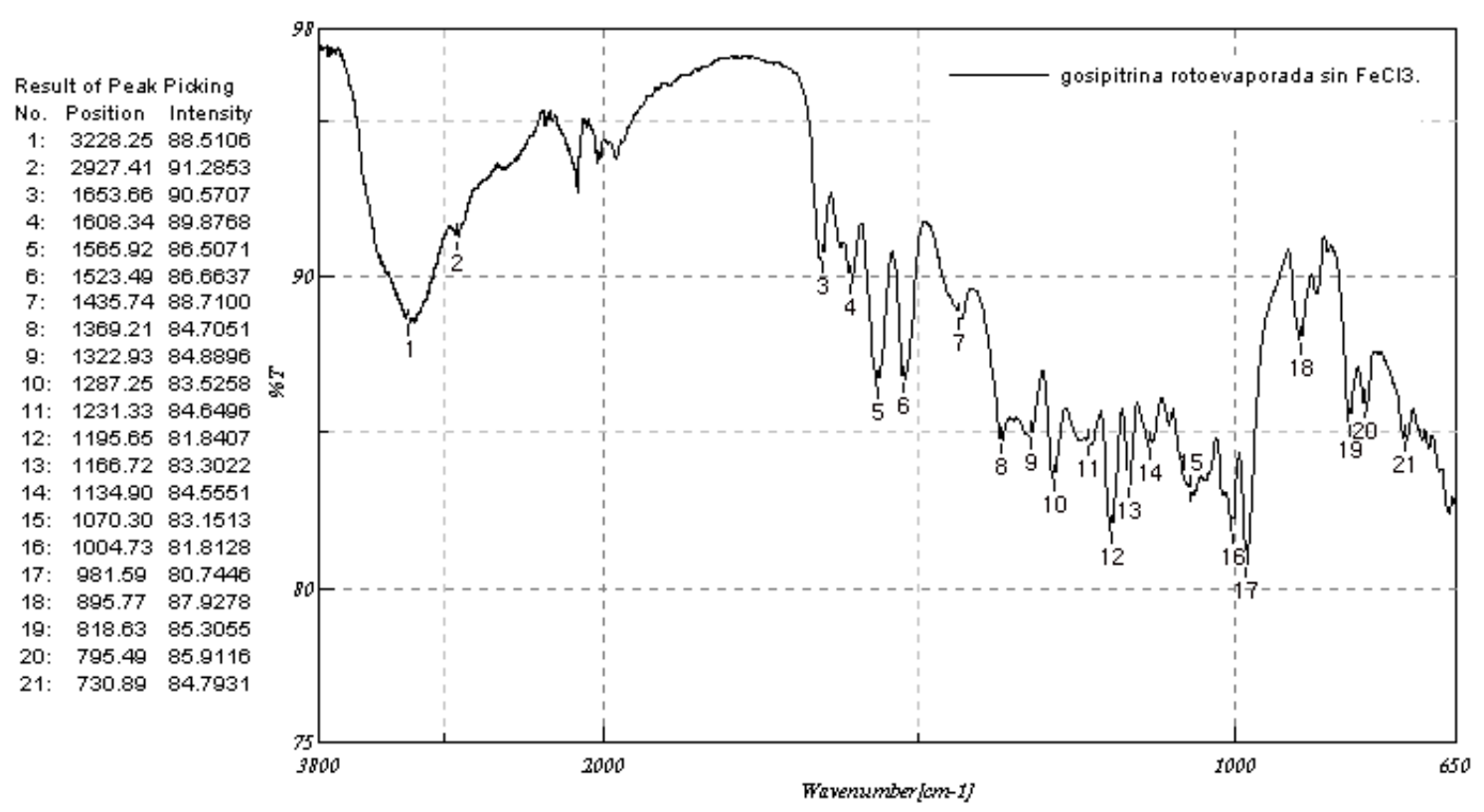

Fig. 4. IR spectrum of gossypitrin without $\mathrm{FeCl}_{3}$.

IR spectra of the reaction products (Fig. 4) exhibited new strong bands with maxima at:

1. $3228.25 \mathrm{~cm}^{-1} \mathrm{OH}$ band, more intense and broad.

2. $1608.24 \mathrm{~cm}^{-1}$ for the stretching vibration of carboxylate. The stretching $\mathrm{C}-\mathrm{H}$ band disappears.

3. $1576.25 \mathrm{~cm}^{-1}$ weak band, overlap by the band before where it situated the stretching C-C band of aromatic compounds, which disappears. 
4. $1375.96 \mathrm{~cm}^{-1}$ band that groups the stretching $\mathrm{C}-\mathrm{O}$ with the rest of the bands.

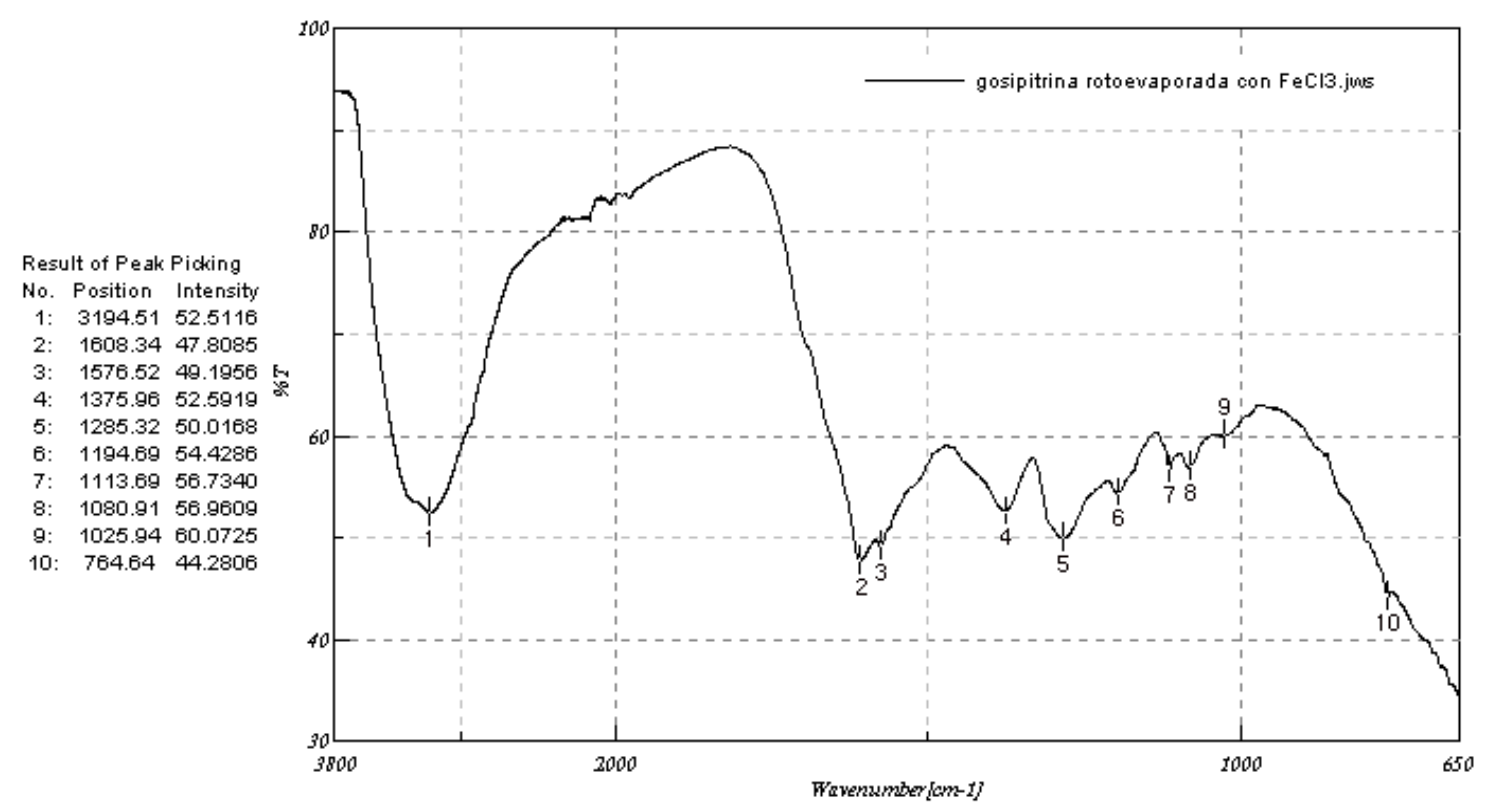

Fig. 5. IR spectrum of gossypitrin with $\mathrm{FeCl}_{3}$.

Comparison of the spectrum of the reaction product with that of pure gossypitrin indicates that the reaction product is a complex of gossypitrin and Fe (III) chloride. The absorption maxima corresponding to $\boldsymbol{y}_{\text {as }}$ of carboxyl group $\left(1608.34 \mathrm{~cm}^{-1}\right)$ for this product are shifted by about $45 \mathrm{~cm}^{-1}$ to low-frequency compared with $y_{\text {as }}$ of the carboxyl group $\left(1653.66 \mathrm{~cm}^{-1}\right)$ in starting gossypitrin.

According to the literature, the most probable complexation mechanism of gossypitrin involves reaction with $\mathrm{Fe}^{3+}$ with reactive groups in the 3, 4-positions of the chromone, although reaction at 4, 5-positions is also possible (Mel'nikova et al., 2002).<smiles>O=c1c(O)c(-c2ccc(O)c(O)c2)oc2c(O)c(OC3OC4C(O)C(O)C(O)C3C4O)cc(O)c12</smiles>

Scheme 1. Structure of gossypitrin.

IR is a spectroscopic technique that analyses the vibrational modes of molecules and molecular groups, allowing bond characterization, and, by comparison with known tabulated data, identification of functional groups; in the case of flavonoids, vibrational spectroscopy has been systematically used to study hydroxyl and carbonyl groups, but more recent 


\section{Mll Macrothink}

Journal of Agricultural Studies

ISSN 2166-0379

2017, Vol. 5, No. 2

technical developments have allowed its application to a broader set of research goals. Similarly, metal complexation by flavonoids is also routinely assessed by vibrational spectroscopy (Siebert \& Hildebrandt, 2007; O’Coinceanainn et al., 2004).

Mass Spectrometry (MS) has proved to be one of the most effective techniques in biomedical research, in special when complex matrixes of biological samples must be analyzed. MS gives data about molecular and ion/fragment masses, leading to a more complex and laborious data analyzing. This problem can be overcome with the construction of structural databases, which allow an easier and quicker data annotation, as well for NMR spectroscopy.

The positive scan mode was used throughout the mass spectrometric experiments. In the full-scan mass spectra of all three complexes, protonated, sodium-cationazed, gossypitrin could be found during the whole measurement. The nomenclature of part of the fragments was according to Domon and Costello (Domon \& Costello, 1988), and "G" was defined to denote gossypitrin in the whole work.

The full-scan mass spectrum of isolated gossypitrin (bottom) and gossypitrin-Fe complexes is shown in Fig. 6. In these spectrums, five gossypitrin-Fe complexes are obviously found, which are peak A $(\mathrm{m} / \mathrm{z}, 536), \mathrm{B}(\mathrm{m} / \mathrm{z}, 592), \mathrm{C}(\mathrm{m} / \mathrm{z}, 1016), \mathrm{D}(\mathrm{m} / \mathrm{z}, 1072)$ and $\mathrm{E}(\mathrm{m} / \mathrm{z}, 1128)$. According to the molecular weight, it was demonstrated that complex A is $[(\mathrm{G}-\mathrm{H}) \mathrm{Fe}]^{+}$(molar ratio of $\mathrm{G} / \mathrm{Fe}=1: 1$ ), complex $\mathrm{B}$ is $\left[(\mathrm{G}-\mathrm{H}) \mathrm{Fe}_{2}\right]^{+}$(molar ratio $\mathrm{G} / \mathrm{Fe}=1: 2$ ), complex $\mathrm{C}$ is $[(2 \mathrm{G}-3 \mathrm{H}) \mathrm{Fe}]^{+}($molar ratio $\mathrm{G} / \mathrm{Fe}=2: 1)$, complex D is $\left[(2 \mathrm{G}-3 \mathrm{H}) \mathrm{Fe}_{2}\right]^{+}($molar ratio $\mathrm{G} / \mathrm{Fe}=2: 2)$ and complex E $\left[(2 \mathrm{G}-3 \mathrm{H}) \mathrm{Fe}_{3}\right]^{+}$(molar ratio $\mathrm{G} / \mathrm{Fe}=2: 3$ ).

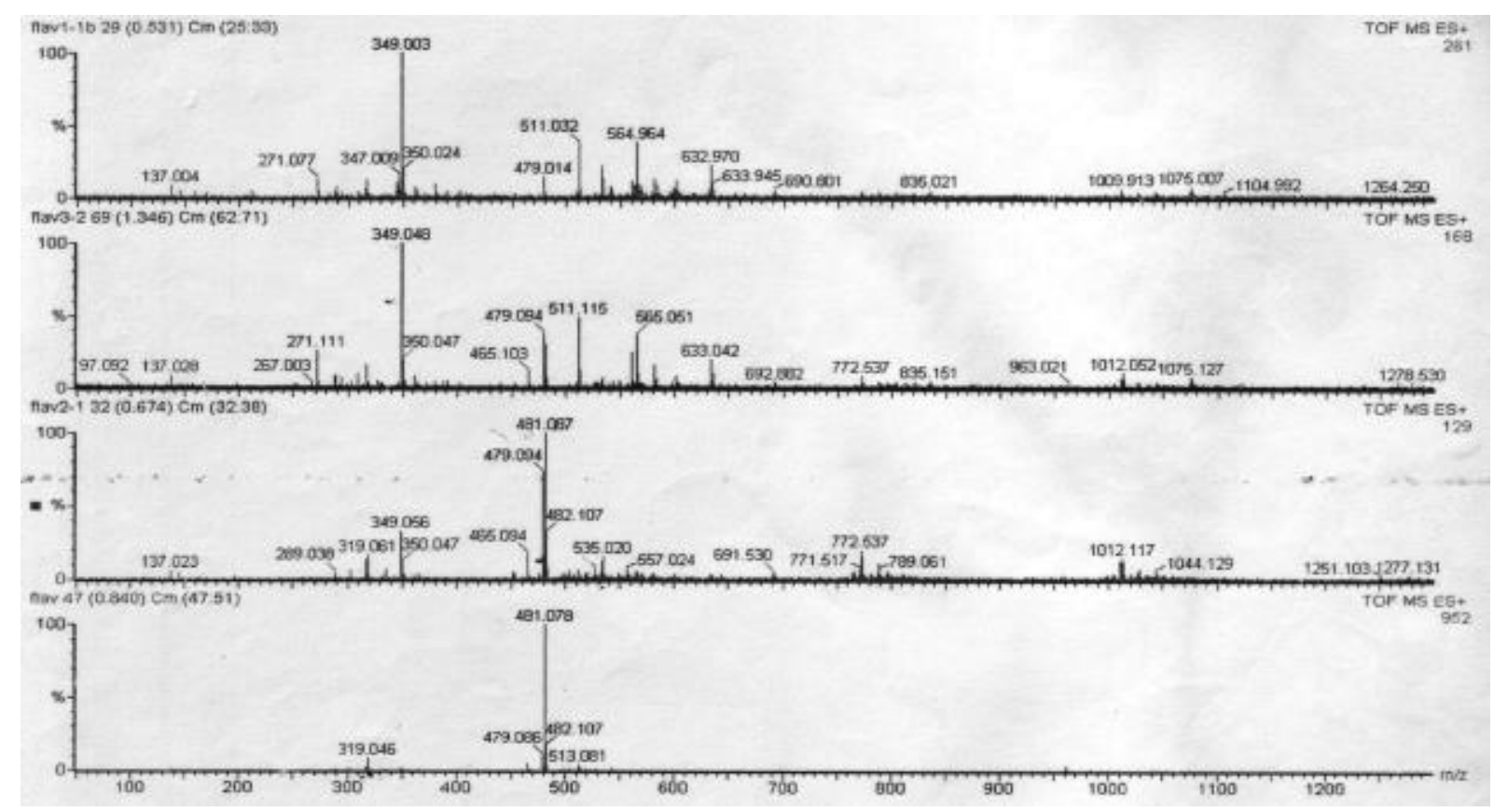

Fig. 6. Full scan mass spectrum of gossypitrin (bottom) and gossypitrin-Fe complexes.

The peaks at $\mathrm{m} / \mathrm{z} 479(\mathrm{M}-1), 481(\mathrm{M}), 482(\mathrm{M}+1)$ and 503, corresponding to protonated gossypitrin $\left([\mathrm{G}+\mathrm{H}]^{+}\right)$and sodium-cationazed gossypitrin $\left([\mathrm{G}+\mathrm{Na}]^{+}\right)$. The main product ions are at $m / z 319$, by the elimination of the one glucose unit (-162 Da), $m / z 536$ from the neutral 


\section{Macrothink}

loss of one Fe ion $(-56 \mathrm{Da}), \mathrm{m} / z 289$ from the loss of $\mathrm{CH}_{2} \mathrm{O}(-30 \mathrm{Da}), \mathrm{m} / z 271$ from the neutral loss of $\mathrm{H}_{2} \mathrm{O}(-18 \mathrm{Da}), \mathrm{m} / z 137$ that corresponding to ${ }^{1,2} \mathrm{~A}$ arises from a RDA before the neutral loss of $\mathrm{m} / z 134\left({ }^{1,3} \mathrm{~B}\right)$, and the ion at $\mathrm{m} / \mathrm{z}, 97$ which is produced by the cleavage of ${ }^{1,2} \mathrm{~A}$ to loss $-40 \mathrm{Da}\left(\mathrm{C}_{2} \mathrm{H}_{2} \mathrm{O}\right)$.

Sequentially, the signal at $\mathrm{m} / \mathrm{z} 536$ and $\mathrm{m} / \mathrm{z}$ 592, arises from the addition of one iron ion in each case $(+56 \mathrm{Da})$, respectively. The ion with molecular weight of 1016 is produced by the addition of one molecule of $\mathrm{G}$ to produce a dimmer (molar ratio 2:1) with a central Fe ion. In this point of the spectrum we can observe the presence of an $\mathrm{m} / \mathrm{z}$ value of 692 due to the neutral loss of two glucose moieties (-324 Da). The same situation occur when the ion at $\mathrm{m} / \mathrm{z}$ 1072 arise from the sum of another iron ion to the dimmer with molar ratio of 2:1 to produce the neutral fragment at $\mathrm{m} / \mathrm{z} 1072$ (molar ratio 2:2).

Finally, we suggest that the ion at $\mathrm{m} / \mathrm{z}, 1278$ arise by addition of a glucose residue of $\mathrm{m} / \mathrm{z}, 150$ from the ion at $m / z 1128$ (complex E), fragment that comes from the neutral reaction between D $(m / z, 1072)$ and another iron ion (+56 Da) (Cavaliere et al., 2005; Satterfield \& Brodbelt, 2001).

\section{Conclusions}

UV, IR and Mass spectrometry played a very important in the structure characterization and fragmentation analysis of gossypitrin-transition metals complexes. Iron ions can form complexes with gossypitrin. For a monomolar gossypitrin-metal complex $\left([(\mathrm{G}-\mathrm{H}) \text { metal }]^{+}\right)$, the fragments came from the neutral loss of a glucose unit, aglycone and sugar chain. For complex $[(2 \mathrm{G}-\mathrm{H}) \text { metal }]^{+}$, the glucose unit, the aglycone and the gossypitrin molecule could be lost during fragmentation. According with ESI-MS results, we obtained a large amount of structural information and only monomers $(1: 1 ; 1: 2)$ and dimmers $(2: 1 ; 2: 2$ and $2: 3)$ are present when gossypitrin react with iron ions, but never trimmers.

It is fair to conclude that although MS methods rarely provide a full molecular determination they are, due to their intrinsic characteristics, the best approach to study flavonoid structures, in complement, when possible, with NMR experiments. For faster cruder screenings, UV absorption data can be used to develop appropriate methods to achieve initial flavonoid class identification.

\section{Acknowledgements}

The authors would like to thank to M.Sc. Alen Nills Baeza Fonte for his help in the acquisition of UV and IR spectrums. We extend our sincere thanks to Center of Genetic Engineering and Biotechnology in Havana for supporting to bring out every detail on the ESI-MS spectrums of gossypitrin and gossypitrin-Fe complexes.

\section{Conflict of Interest Statement}

We declare that we have no conflict of interest. 


\section{References}

Abad-García B, Berrueta L. A, Garmon-Lobato S, Gallo B, Vicente F. (2009). A general analytical strategy for the characterization of phenolic compounds in fruit juices by high-performance liquid chromatography with diode array detection coupled to electrospray ionization and triple quadrupole mass spectrometry. J. Chromatogr. A 1216, 5398-5415. https://doi.org/10.1016/j.chroma.2009.05.039

Bors W, Heller W, Michel C, \& Saran M. (1990). Flavonoids as antioxidants: determination of radical-scavenging efficiencies. Methods in Enzymology, 186, 343-355.

https://doi.org/10.1016/0076-6879(90)86128-I

Cavaliere C, Foglia P, Pastorini E, Samperi R, \& Lagana A. (2005). Identification and mass spectrometric characterization of glycosylated flavonoids in Triticum durum plants by high-performance liquid chromatography with tandem mass spectrometry. Rapid Commun. Mass Spectrom. 19, 3143-3158. https://doi.org/10.1002/rcm.2185

Davis B. D, \& Brodbelt J. S. (2007). Regioselectivity of human UDP-glucuronosyl-transferase 1A1 in the synthesis of flavonoid glucuronides determined by metal complexation and tandem mass spectrometry. Journal of the American Society for Mass Spectrometry, 19(2), 246-256. https://doi.org/10.1016/j.jasms.2007.11.004

Davis B. D, Needs P. W, Kroon P. A, \& Brodbelt J. S. (2006). Identification of isomeric flavonoid glucuronides in urine and plasma by metal complexation and LC-ESIMS/MS. Journal of Mass Spectrometry, 41(7), 911-920, 2006. https://doi.org/10.1002/jms.1050

Domon B, Costello CE. (1988). A systematic nomenclature for carbohydrate fragmentations in Fab-MsMs spectra of glycoconjugates. Glycoconjugate Journal, 5, 397.

https://doi.org/10.1007/BF01049915

Fernandez, M. T.; Mira, M. L.; Florêncio, M. H., \& Jennings, K. R. (2002). Iron and copper chelation by flavonoids: an electrospray mass spectrometry study. Journal of Inorganic Biochemistry, 92, 2, 105-111. https://doi.org/10.1016/S0162-0134(02)00511-1

Hollman P. C, Bijsman M. N, van Gameren Y, Cnossen E. P, de Vries J. H, \& Katan M. B. (1999). The sugar moiety is a major determinant of the absorption of dietary flavonoid glycosides in man. Free Radical Research, 31(6), 569-573.

https://doi.org/10.1080/10715769900301141

Kumar S, \& A. K. Pandey A. K. (2013b). Phenolic content, reducing power and membrane protective activities of Solanum xanthocarpum root extracts. Vegetos, 26(301-307). https://doi.org/10.5958/j.2229-4473.26.1.043

Kumar S, Gupta A, \& Pandey A. K. (2013c). Calotropis procera root extract has capability to combat free radical mediated damage. ISRN Pharmacology, vol. 2013, Article ID 691372, 8 pages.

Kumar S, Mishra A, \& Pandey A. K. (2013a). Antioxidant mediated protective effect of Parthenium hysterophorus against oxidative damage using in vitro models. BMC 
Complementary and Alternative Medicine, 13, article120.

Leopoldini M, Russo N, Chiodo S, \& Toscano M. (2006). Iron chelation by the powerful antioxidant flavonoid quercetin. Journal of Agricultural and Food Chemistry, 54(17), 6343-6351. https://doi.org/10.1021/jf060986h

Mahomoodally M. F, Gurib-Fakim A, \& Subratty A. H. (2005). Antimicrobial activities and phytochemical profiles of endemic medicinal plants of Mauritius. Pharmaceutical Biology, 43(3), 237-242. https://doi.org/10.1080/13880200590928825

Mel'nikova NB, Ioffe ID, \& Tsareva LA. (2002). Reaction of Bioflavonoids with Copper (II) Acetate in Aqueous Solution. Chemistry of Natural Compounds, 38(1), 33-39.

https://doi.org/10.1023/A:1015721529647

Mishra A, Kumar S, \& Pandey A. K. (2013a). Scientific validation of the medicinal efficacy of Tinospora cordifolia. The Scientific World Journal, vol. 2013, Article ID 292934.

https://doi.org/10.1155/2013/292934

Mishra A, Sharma A. K, Kumar S, Saxena A. K, \& Pandey A. K. (2013b). Bauhinia variegata leaf extracts exhibit considerable antibacterial, antioxidant and anticancer activities. BioMed Research International, vol. 2013, Article ID 915436, 10 pages.

O’Coinceanainn M, Bonnely S, Baderschneider B, \& Hynes M. J. (2004). Reaction of iron(III) with theaflavin : complexation and oxidative products. Journal of Inorganic Biochemistry, 98(4), 657-663. https://doi.org/10.1016/j.jinorgbio.2003.12.018

Pandey A. K. (2007). Anti-staphylococcal activity of a pan-tropical aggressive and obnoxious weed Parihenium histerophorus: an in vitro study. National Academy Science Letters, 30(11-12), 383-386. https://doi.org/10.1039/CT9160900145

Parkin, A. G. (1916). The Coloring Matter of Cotton Flowers. Part III. Journal of the Chemical Society London, 109, 145-154. http://dx.doi.org/10.1039/CT9160900145

Pikulski M, Aguilar A, \& Brodbelt J. S. (2007). Tunable Transition Metal-Ligand Complexation for Enhanced Elucidation of Flavonoid Diglycosides by Electrospray Ionization Mass Spectrometry. Journal of the American Society of Mass Spectrometry, 18(3), 422-431. https://doi.org/10.1016/j.jasms.2006.10.011

Ratty A. K, \& Das N. P. (1988). Effects of flavonoids on nonenzymatic lipid peroxidation: structure-activity relationship. Biochemical Medicine and Metabolic Biology, 39(1), 69-79. https://doi.org/10.1016/0885-4505(88)90060-6

Ren J, Meng S, Lekka C. E, \& Kaxiras E. (2008). Complexation of Flavonoids with Iron: Structure and Optical Signatures. The Journal of Physical Chemistry B, 112, 6, 1845-1850. https://doi.org/10.1021/jp076881e

Rice-Evans C. A, Miller N. J, \& Paganga G. (1996). Structure antioxidant activity relationships of flavonoids and phenolic acids. Free Radical Biology and Medicine, 20(7), pp.933-956. https://doi.org/10.1016/0891-5849(95)02227-9 


\section{Al Macrothink}

Journal of Agricultural Studies

ISSN 2166-0379

2017, Vol. 5, No. 2

Satterfield M, \& Brodbelt J. S. (2000). Enhanced Detection of Flavonoids by Metal Complexation and Electrospray Ionization Mass Spectrometry. Analytical Chemistry, 72, 5898-5906. https://doi.org/10.1021/ac0007985

Satterfield M, \& Brodbelt J. S. (2001). Structural Characterization of Flavonoid Glycosides by Collisionally Activated Dissociation of Metal Complexes. J Am Soc Mass Spectrometry. 12, 537-549. https://doi.org/10.1016/S1044-0305(01)00236-7

Siebert, F., \& Hildebrandt, P. (2007). Vibrational Spectroscopy in Life Science (1st edition), Wiley VCH, ISBN 978-3527405060, ISA. https://doi.org/10.1002/9783527621347

Van A, van den Berg S. A. B. E, Tromp D. J. M. N. J. L, et al. (1996). Structural aspects of antioxidant activity of flavonoids. Free Radical Biology and Medicine, 20(3), 331-342. https://doi.org/10.1016/0891-5849(95)02047-0

Vukics, V., \& Guttman, A. (2010). Structural characterization of flavonoids glycosides by multi-stage mass spectrometry. Mass Spectrom. Rev. 29, 1-16.

\section{Copyright Disclaimer}

Copyright for this article is retained by the author(s), with first publication rights granted to the journal.

This is an open-access article distributed under the terms and conditions of the Creative Commons Attribution license (http://creativecommons.org/licenses/by/4.0/). 